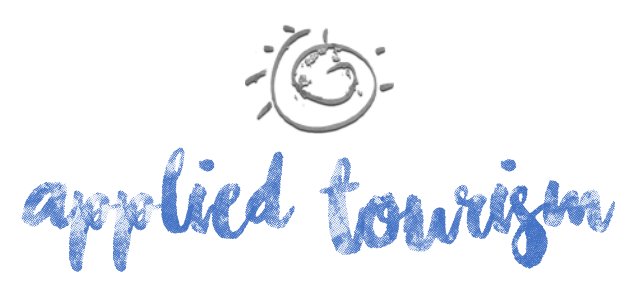

Volume 2, número 1,2017, p. 111-127

\title{
LAGO PARANOÁ DE BRASÍLIA/DF: análise da percepção dos frequentadores da orla motivados por atividlades de lazer a respeito do espaço existente
}

\author{
Luiz Daniel Muniz Junqueira \\ Doutorando em Turismo e Hotelaria - UNIVALI \\ Professor do Instituto Federal de Brasília - IFB \\ luiz.junqueira@ifb.edu.br
}

Recebido: 17 de junho, 2016

Aprovado: 17 de novembro, 2016

\section{RESUMO}

Esse estudo identificoualgumas áreas de lazer da orla do Lago Paranoá de Brasilia, buscando analisar a percepção da população nas formas de utilização destes espaços. Apoiou-se na abordagem do lazer para fundamentar esta pesquisa, assim como as categorias de análise do espaço geográfico. A percepção dos frequentadores da orla do Lago Paranoá foi obtida por meio de entrevistas com a população que se encontravam nas margens do lago por meio do método do Discurso do Sujeito Coletivo de Lefèvre \& Lefèvre. A partir destas entrevistas, elaborou-se um discurso coletivo que caracterizou a forma com que são aproveitados e vistos os espaços na orla do lago. Os resultados da pesquisa demonstraram que o espaço da orla do Lago Paranoá tem um grande potencial de utilização para o lazer, no entanto faltam políticas de ocupação mais eficientes, privilegiando a parceria público-privado.

Palavras-chave: Lago Paranoá de Brasilia/DF. Frequentadores. Lazer. 


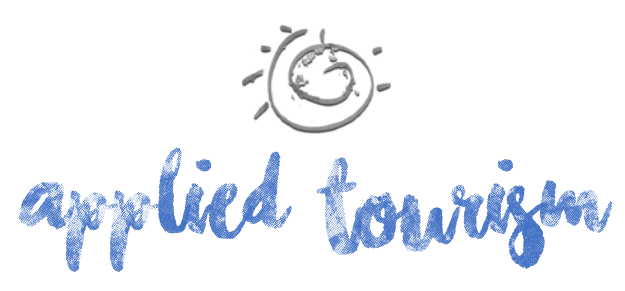

Volume 2, número 1,2017, p. 111-127

\section{INTRODUÇÃO}

Compreender o lazer enquanto relação social de uma comunidade é pensar no crescimento e desenvolvimento social. As vantagens que o lazer propicia para uma sociedade são imensas considerando o momento histórico. Com o avanço tecnológico e cada vez mais o aumento das obrigações e responsabilidades do homem na comunidade inserida, a fuga desse contexto traz uma nova percepção e tranquilidade para continuar esses

enfrentamentos. É necessária a vivência desse momento de fuga das obrigações para melhorar a qualidade de vida das pessoas. O lazer pode fazer isso.

Porém, a simples existência de áreas de lazer não garante a sua utilização. É necessário verificar se as áreas existentes satisfazem seu objetivo principal: o desenvolvimento individual e coletivo, além do convívio social. O estudo proposto está relacionado ao contexto de Lazer, Espaços Públicos e Desenvolvimento Social, tendo-se como espaço de análise a orla do Lago Paranoá de Brasília, localizado no Distrito Federal.

Considerando o determinante histórico da ocupação espacial da orla do Lago Paranoá, essa pesquisa teve como objetivo analisar a percepção dos frequentadores da orla motivados por atividades de lazer a respeito do espaço existente.

A população de Brasília necessita de áreas de lazer com a finalidade de promover o desenvolvimento ea integração social. Desde o projeto inicial de Lúcio Costa (COSTA, 1991) para a construção do Plano Piloto de Brasília, o espaço da orla do Lago Paranoá era destinado para a utilização pública. Considerando o projeto inicial, as ocupações na orla só poderiam ser feitas mediante o interesse público. Esse estudo contribui demonstrando a percepção da população local com os usos e ocupações da orla. 


\section{(6)

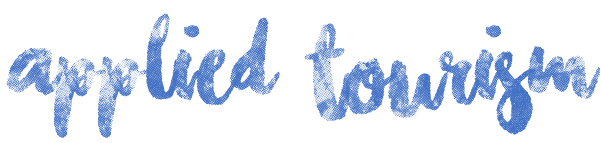

Volume 2, número 1, 2017, p. 111-127

\section{REFERENCIAL TEÓRICO}

\section{Definindo espaço: categorias de análise}

Considera-se que o espaço é formado pelas relações da natureza com o homem e suas relações sociais vigentes. Tudo que compõe o meio em que o homem habita pode ser considerado espaço. O que dá vida a essas relações são suas interações com os processos sociais. Castells (1983, p. 182) diz que:

O espaço é um produto material em relação com outros elementos materiais - entre outros, os homens, que entram também em relações sociais determinadas, que dão ao espaço (bem como aos outros elementos da combinação) uma forma, uma função, uma significação social. Portanto, ele não é uma pura ocasião de desdobramento da estrutura social, mas a expressão concreta de cada conjunto histórico, no qual uma sociedade se especifica.

Para Santos (1997, p. 49):

Um conceito básico é que o espaço constitui uma realidade objetiva, um produto social em permanente processo de transformação. O espaço impõe sua própria realidade; por isso a sociedade não pode operar fora dele. Conseqüentemente, para estudar o espaço, cumpre apreender sua relação com a sociedade, pois é esta que dita a compreensão dos efeitos dos processos (tempo e mudança) e especifica as noções de forma, função e estrutura, elementos fundamentais para a nossa compreensão da produção de espaço.

A relação entre a formação do espaço da orla do Lago Paranoá de Brasilia e a sociedade está diretamente ligada. Desse modo, a compreensão do espaço deve-se apoiar na compreensão da realidade social, baseada no contexto histórico em que a sociedade foi evoluindo até o presente momento.

A Função do Lago Paranoá, além de amenizar o clima seco da região, é promover a escala bucólica da cidade, de acordo com o projeto inicial de Lúcio Costa, sendo assim, um espaço voltado principalmente para o lazer da comunidade. A Função está diretamente ligada a Forma, e a sua Forma atual apresenta indícios desta Função, pois existem diversas áreas 


\section{(6)

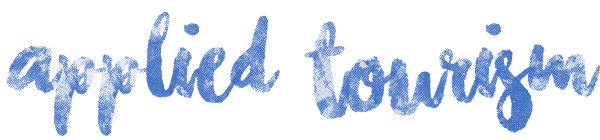

Volume 2, número 1,2017, p. 111-127

A manutenção da orla do Lago Paranoá de Brasília como sendo um local de encontro social é importante para a própria comunidade, manifestando assim um sentimento de coletividade o que induz a um desenvolvimento social amplo.

\section{Lazer: conceitos e características}

Percebe-se que o tempo livre é, em alguns casos, bastante reduzido, e isso reflete diretamente na disponibilidade de tempo em que as pessoas têm para o lazer. Nos estudos de caráter sociológico de Dumazedier (1999, p. 58), o lazer não corresponde apenas às necessidades autênticas das pessoas. Essas necessidades se interam com as condições do mercado econômico, com as tradições éticas e com as políticas vigentes, caracterizando-se pelos determinismos sociais. Porém, a liberdade de escolha dentro do tempo de lazer é uma realidade, mesmo que limitada.

Para Dumazedier (2001, p. 34):

O lazer é um conjunto de ocupações às quais o indivíduo pode entregar-se de livre vontade, seja para repousar, seja para divertir-se, recrear-se e entreter-se ou, ainda para desenvolver sua informação ou formação desinteressada, sua participação social voluntária ou sua livre capacidade criadora após livrar-se ou desembaraçar-se das obrigações profissionais, familiares e sociais.

Marcellino (2002, p. 14) afirma que "[...] além do descanso e do divertimento outra possibilidade ocorre no lazer e, normalmente, não é tão perceptível. Trata-se do desenvolvimento pessoal e social que o lazer enseja [...]". Dumazedier (2001, p. 32) concorda ao dizer que existem três funções mais importantes do lazer: a função de descanso; divertimento, recreação e entretenimento; e desenvolvimento. E, ainda, Andrade (2001, p. 21) complementa ao afirmar que:

O lazer é essencial à vida humana equilibrada, saudável e produtiva. É indispensável à conservação e ao dinamismo regular do ecossistema humano, cujo pontoideal de produtividade se manifesta nas atividades espontâneas e nas atitudes planificadas de expansão e de retração, de tensão e de relaxamento. 


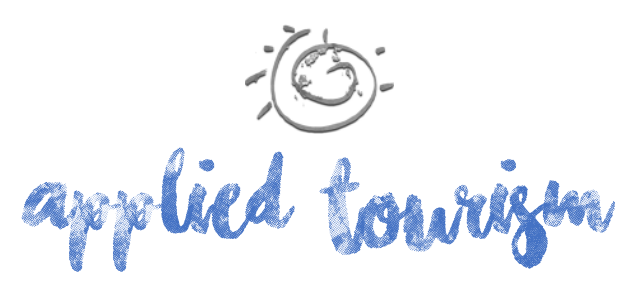

Volume 2, número 1,2017, p. 111-127

Evidencia, dessa forma, a importância do lazer para o equilíbrio psicológico humano, no qual a busca pelo lazer traz consequiências benéficas e agradáveis ao nosso organismo. O reflexo desse equilíbrio mental também reflete na sociedade, pois a força produtiva (o ser humano) mantém um desenvolvimento pessoal e coletivo.

Segundo Camargo (2003, p. 97) o lazer é:

[...] um conjunto de atividades gratuitas, prazerosas, voluntárias e liberatórias, centradas em interesses culturais, físicos, manuais, intelectuais, artísticos e associativos, realizadas num tempo livre roubado ou conquistado historicamente sobre ajornada de trabalho profissional e doméstico e que interferem no desenvolvimento pessoal e social dos indivíduos.

O tempo de lazer, enquanto um tempo de fruição, torna-se também um tempo de aprendizagem, aquisição e integração, diverso dos sentimentos, conhecimentos, modelos e valores da cultura, no conjunto das atividades na qual o indivíduo está enquadrado. O lazer poderá vir a ser uma ruptura: a cessação de atividades impostas pelas obrigações profissionais, familiares e sociais e, ao mesmo tempo, o reexame das rotinas, estereótipos e idéias já prontas que concorrem para a repetição e especialização das obrigações cotidianas (DUMAZEDIER, 2001).

A orla do Lago Paranoá é considerada um espaço privilegiado para a realização de atividades sociais dentro do contexto urbano de Brasília. Devido a isso, as atividades de lazer proporcionadas pela capacitação e consolidação da orla como uma referência para a cidade devem ser relacionadas à construção e transformação do espaço.

A sociabilidade da orla do Lago Paranoá mediante a capacitação de infraestrutura é um processo de valorização do espaço do local, pois, com infraestrutura os lugares se tornam mais acessíveis e, consequentemente, mais frequentados pela população. 


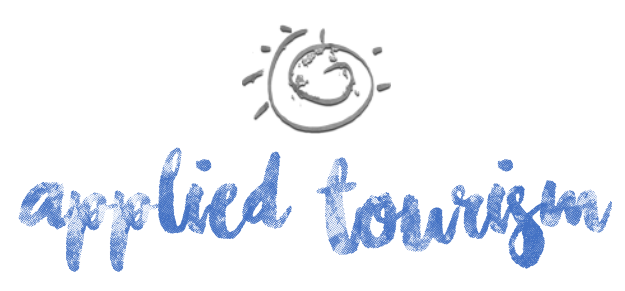

Volume 2, número 1,2017, p. 111-127

\section{METODOLOGIA}

A abordagem metodológica desse trabalho é a pesquisa qualitativa com técnicas bibliográfica e de levantamento. As perguntas da entrevista foram formuladas baseando-se nos critérios definidos para identificar a percepção dos frequentadores da orla a respeito do espaço existente para o lazer.

O método de análise adotado foi o Discurso do Sujeito Coletivo (DSC) de Lefèvre \& Lefèvre (2003). Essa técnica consiste em elaborar um Discurso do Sujeito Coletivo (DSC) por meio de Expressões-chave (ECH), Idéias Centrais (IC) e Ancoragens (AC), com a finalidade de descrever o campo semântico observado da população entrevistada. O DSC faz produzir o sujeito social ou coletivo do discurso e o discurso correspondente, fazendo o social falar a partir do individual.

As perguntas formuladas para a construção do DSC abordaram questões a respeito do motivo a frequentarem a orla do Lago Paranoá, qual meio de comunicação conheceram tal área de lazer, como classificam os acessos e as sinalizações até as áreas de lazer da orla do lago, o que consideram a respeito do que é oferecido enquanto espaço público na orla, o conhecimento sobre leis de ocupação do entorno do lago e a opinião em relação à privatização das áreas da orla do Lago Paranoá.

As entrevistas semiestruturadas foram realizadas com vinte pessoas, divididas em quatro pontos da orla do lago. A população delimitada para a pesquisa abrange a comunidade do Distrito Federal que frequenta a orla do Lago Paranoá de Brasília para o lazer. A elaboração da entrevista foi não-intencional, ou seja, foram escolhidas aleatoriamente as pessoas que responderam as questões.

Foram escolhidos intencionalmente quatro espaços abertos de lazer para a comunidade em locais diferentes da orla do Lago Paranoá. Considerou, também, o nível de infraestrutura, variando de locais com boa estrutura e locais com pouca ou sem estrutura. Os locais da 


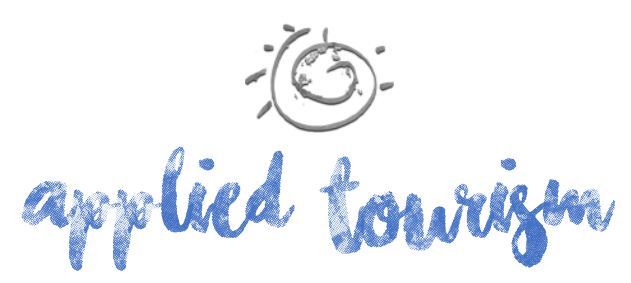

Volume 2, número 1,2017, p. 111-127

entrevista foram a área de lazer do Lago Norte, o Shopping Pier 21, o centro de lazer Pontão Sul e o ParqueErmida Dom Bosco. As entrevistas foram realizadas nos dias 24 (área de lazer do Lago Norte e Shopping Pier 21) e 26 (centro de lazer Pontão Sul e parque Ermida Dom Bosco) de maio de 2005.

\section{RESULTADOS E DISCUSSÕES}

No primeiro DSC encontrou-se os motivos que levam os moradores de Brasília a frequentar a orla do Lago Paranoá, assim, foi possível compreender que a sociedade reconhece que existem poucos espaços públicos voltados para o lazer na cidade. As pessoas se deslocam para a orla do lago com a finalidade de aproveitar o dia e contemplar a paisagem, sendo a importância do clima de Brasília outro fator importante para a atração das pessoas para as áreas próximas ao lago. Porém, percebeu-se na entrevista que parte da sociedade não se importa com as áreas do lago, frequentando apenas por motivos de trabalho e necessidade.

Outro aspecto importante percebido no discurso foi que a comunidade entende que as melhores áreas de lazer da orla são os clubes particulares, mas somente uma parte da sociedade tem acesso a eles, pois se voltam para a classe média. Um espaço público destacado nas entrevistas foi o Pontão Sul, pois percebeu-se que nesse local as pessoas encontram segurança e conforto. Portanto, o primeiro DSC foi:

Brasilia tem poucas opções de lazer e a orla do Lago Paranoá é um lugar muito bom para passear, pescar, tomar sol, ficar bronzeado. Venho para curtir o visual, a diversidade da paisagem, o ar puro, a beleza do lago e o vento, tudo isso, a paisagem aqui é linda, logo, é um bom lugar para aproveitar o dia. Quando não tem nada pra fazer vou pra orla para me divertir, para ocuparo tempo. Umaárea de lazer boa para conversar, aproveitar os bares, para diversão. Venho aqui também na busca pela tranqüilidade e o sossego que fazem as pessoas se sentirem mais calmas, para ter uma paz espiritual. A agradabilidade que a umidade do lago proporciona traz um bem estar, já que o clima de Brasília é muito seco. É bom para as crianças. $\mathrm{Na}$ orla você consegue ver o lago, o céu, portanto se sente em um lugar aberto. É bem legal estar em contato com a natureza, estar em contato com a parte aquática da cidade. Já freqüentei a orla mais vezes, atualmente é esporádico, meu filho que quis vir aqui para fazer um lanche, mas não freqüento aqui. Venho para a orla do lago porque trabalho como motorista. No entanto, as melhores áreas de lazer da 


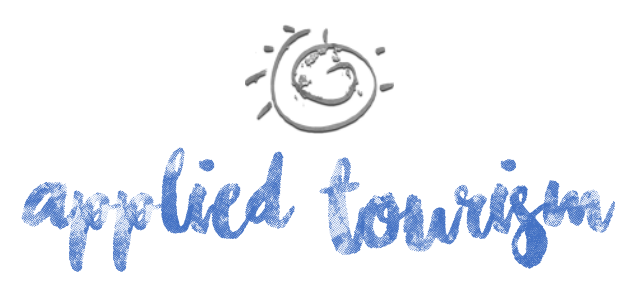

Volume 2, número 1,2017, p. 111-127

O entorno do Lago Paranoá possui uma boa infraestrutura de acesso concentrado nas áreas mais conhecidas e investidas, como os clubes particulares e o Pontão Sul. A preservação da orla consiste na forma de implantação da infraestrutura, então, algumas vias de acesso para as áreas de lazer na orla devem continuar de forma mais simples, como estradas de terra, para diminuir o impacto no ecossistema local.

Para o quarto DSC o interesse foi investigar como a população percebe as sinalizações voltadas para as áreas de lazer encontradas no entorno do Lago. Com isso, o discurso apresentou que os residentes da cidade não reparam na sinalização e por conhecer a região informaram que não necessitam de sinalizações. Mas, o mesmo discurso informou da dificuldade em encontrar as áreas de lazer por quem não conhece o local, pois falta sinalização e as que existem são precárias. Embora o discurso voltou-se para relatar a insuficiência de sinalização na orla, revelou que para o entendimento da população os lugares mais conhecidos possuem uma boa sinalização, principalmente quando tem algum evento. Portanto, o quarto DSC é:

Quem mora em Brasília está acostumado com a cidade, então não repara na sinalização, e conhecendo a cidade, encontra facilmente os locais de lazer da orla, não precisa de sinalização. Já para quem não mora em Brasília não entende os endereços porque aqui é diferente do resto do país. Para quem não conhece os locais de lazer não chega com facilidade, tem que sair perguntando, portanto poderia ter mais sinalizações, são insuficientes, não tem indicação. A maioria das pessoas entra por lugares alternativos porque não sabem como chegar aos locais de lazer e as sinalizações que existem são precárias. Porém, nos lugares mais conhecidos a sinalização é ótima, adequada, qualquer via tem sinalização indicando as áreas, quem quiser chegar chega tranqüilo. Quando tem festa ou algum evento é tudo bem sinalizado. Atualmente as sinalizações são bem melhores e para o Pontão e a Ermida são adequadas.

Somente os espaços públicos mais conhecidos e populares da orla do Lago Paranoá possuem sinalização, enquanto outras áreas de lazer não possuem placa informativa. O Governo do Distrito Federal deveria implantar um roteiro de placas na orla do lago para sinalizar e apontar as áreas públicas de lazer promovendo assim a integração da população para os espaços públicos, pois com uma sinalização adequada o fluxo de pessoas para as áreas de lazer da orla pode aumentar. 


\section{(2) \\ ayeliced towrigh}

Volume 2, número 1,2017, p. 111-127

$\mathrm{Na}$ quinta pergunta o discurso revelou o que a população compreende como espaço público na orla do lago e se está satisfeita com o que é oferecido. O significado desse discurso apresenta o ponto de vista da população com a realidade da orla do Lago Paranoá de Brasília. Sendo assim, o discurso proferido pelos frequentadores apresentou que a orla pode ser mais bem aproveitada e necessita de mais diversidade para seu espaço, existindo vários locais que não estão sendo utilizados, estão abandonados.

Na orla do Lago Paranoá somente alguns lugares contam com infraestrutura adequada, o que é muito pouco em comparação com o tamanho do espaço. O discurso destacou que os clubes atendem as necessidades de integração social, mas o público é reduzido, criando a segregação social para quem não tem condições financeiras de se associar a um clube particular. O quinto discurso se apresenta como:

Embora haja cinema, clubes, restaurantes e sorveterias que atendem as necessidades do dia a dia, o que é oferecido no espaço da orla é insuficiente, poderia ter mais opções de lazer, mudar algumas coisas, falta mais diversidade, existem vários locais que não estão sendo utilizados, estão abandonados. A orla é pouco explorada, poderiam colocar uma infraestrutura voltada mais para o público, aqui não tem demanda porque não tem atrativos. Brasília é extremamente carente de centros de integração social. Quando tem um feriado e as cidadessatélites se deslocam para Brasília, a orla não tem espaço suficiente para todos, pois tem poucas faixas de aproveitamento. No projeto inicial era para ter um calçadão que beirasse todo o lago, mas não tem e a ocupações irregulares na orla do lago dificultam os acessos e atrapalham a utilização dos espaços públicos. Faltam sanitários, faltam quiosques, falta tudo, não tem infra-estrutura adequada. Este espaço poderiaser mais bem aproveitado devido ao tamanho do lago. Aqui só atende a necessidade de quem mora perto, principalmente no Lago Sul e todos que moram no Lago Sul têm condições financeiras de se associar a um clube. A orla é única e exclusiva para quem tem poder aquisitivo. Quem não tem dinheiro não tem acesso aos bons locais da orla, que são os clubes. Ou você se associa a um clube ou não freqüenta bons lugares da orla do lago. A utilização da orla fica restrita a quem tem dinheiro.

Com essa área enorme no entorno do Lago Paranoá o aproveitamento poderia ser bem melhor, porém, os espaços públicos de lazer concentram em alguns pontos da orla influenciados pelas construções de residências particulares, o que vai contra a utilização da 


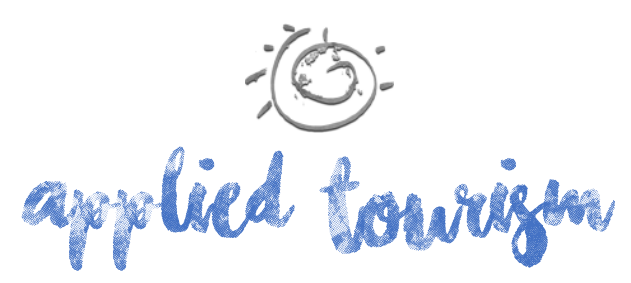

Volume 2, número 1,2017, p. 111-127

orla pela comunidade. Os clubes particulares são reconhecidos como a melhor forma de utilização da orla. Tal fato parece inverter a lógica dos espaços públicos, pois a ocupação do entorno do lago não pode se restringir aos clubes, pois existe a necessidade de áreas públicas abertas na orla para pessoas que não tenham condições financeiras de frequentar estas instalações de lazer.

A percepção buscada na sexta pergunta foi sobre o conhecimento dos frequentadores a respeito das leis que regem a ocupação do entorno do Lago Paranoá. Sendo assim, a população discursou que não conhece as leis da forma como elas são, somente de ouvir falar e sabe que tem a lei de preservação da mata original que evita a construção na orla do lago.

Embora a comunidade tenha conhecimento das leis, afirmam que existe muita invasão de áreas públicas no entorno do lago, o que evita o acesso da população para essas áreas. O discurso revelou que a população acredita que os invasores da orla do lago são pessoas de alto poder aquisitivo, o que dificulta a desapropriação das áreas pelo governo. O sexto DSC se apresenta:

Conheço de ouvir falar, sei que existe. Tem a lei dos 30 metros, onde não pode fazer construção na beira do lago, no qual tem que conservar a mata original, a vegetação original, são leis ambientais. Tem também a lei distrital e a federal, não conheço todas elas especificamente, mas sei que existe, ouvi falar por meio da televisão, mas não a tenho em mente. Sei que tem muito invasor nas áreas públicas da orla do lago, no qual invadem muita área verde. A orla do Lago Paranoá de Brasília era para ter uma área verde muito mais aberta, mas as casas próximas ao lago invadiram essa área verde. A população poderia ter muito mais acesso e não tem porcausa disso. As invasões são de juízes, promotores públicos, alto escalão do governo, pessoas que possuem dinheiro, invadem mesmo conhecendo as leis. Várias matérias do jornal já mostraram essa invasão.

As leis existem, porém a comunidade não conhece plenamente como ela é e nem se está sendo cumprida. Outro fato que inibe a aplicação da lei de ocupação do entorno do Lago Paranoá é o fato de que as ocupações irregulares são de pessoas que possuem dinheiro, portanto, difícil para o governo derrubar qualquer construção. 


\section{(2)

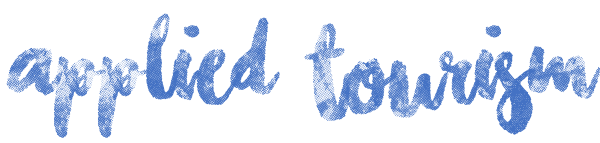

Volume 2, número 1,2017, p. 111-127

Para finalizar a compreensão da população que frequenta a orla do Lago elaborou-se a pergunta para as pessoas discursarem sobre a privatização do espaço da orla. Desse modo, o sétimo DSC apresentou que existem pessoas a favor da privatização, contanto que seja para o bem-estar coletivo e de preservação do local, com a implantação de infraestrutura voltada para a população e não de residências particulares. O discurso revelou, ainda, o entendimento dos frequentadores pelo descaso do governo local em preservar o entorno do Lago Paranoá, não manifestando nenhum investimento no local. O sétimo DSC diz:

Em alguns casos sou a favor e em outros contra, pois tem muita casa que polui demais e acaba com toda a orla do lago. Tem casa que é praticamente dentro do lago, então acho que isso é errado. Sou contra a privatização de residências. Acho errado porque existe uma lei para preservar todaa orla e ela é de toda a população. O governo deveria tomar medidas mais enérgicas, mas não tem controle sobre isso, é muito desorganizado e dáacesso para que as pessoas cerquem suas casas até a orla do lago. O governo não se preocupa com os pobres, pois é uma área pública e a privatização só favorece os ricos. Ninguém tem que tomar posse de uma área verde que é da União, é público. Brasíliaé tombada pelo patrimônio histórico da União e uma área pública não pode ser privatizada. A orla existe para a sociedade, para atender ao público. É uma sacanagem a privatização dos bens públicos em Brasília. Não acho legal privatizar, pois vai acabar com a orla. Se não tiver cuidado com a orla logo terá problemas de preservação. Poderia deixar do jeito que está, onde todos podem usufruir da orla. Se privatizar a orla irá elitizar o espaço. Porém, a privatização tendo um retorno de bem-estar para a população mantendo o ambiente do jeito queé, privatizando para o lazer sou a favor, pois o governo não investe mesmo.

A privatização da orla do Lago Paranoá não deve ser feita de forma particular, mas de acordo com o proposto para sua utilidade, que é a de propiciar o lazer para toda a comunidade. Portanto, é importante a implantação de infraestrutura na orla, porém, como o governo não tem condições de realizar essas construções, a saída é criar uma parceria com os agentes privados para financiar os projetos.

\section{CONSIDERAÇÕES FINAIS}

Com a análise das sete perguntas aplicadas nos frequentadores da orla do Lago Paranoá de Brasília foi possível entender que o espaço do entorno do lago é pouco explorado em 


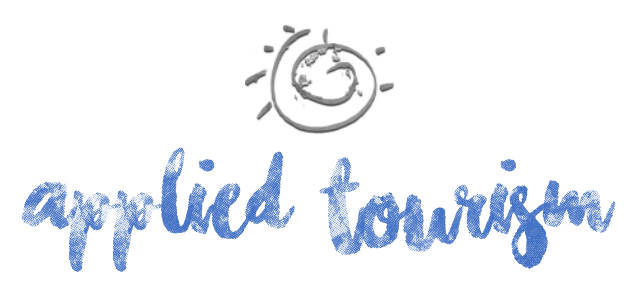

Volume 2, número 1,2017, p. 111-127

relação as suas potencialidades e que a população considera importante esses espaços públicos, embora as áreas não apresentem uma infraestrutura adequada para receber a população com conforto. O espaço relacionado do meio físico com a população revela o significado da importância da orla para a população local e suas relações com o meio ecológico.

A finalidade da entrevista foi compreender a importância do Lago Paranoá para a população local e os resultados encontrados nos discursos apresentados revelaram que esse espaço tem todo potencial de se tornar um grande centro de lazer da cidade, pois mesmo com a infraestrutura inadequada para receber o público a orla do lago atrai uma massa significativa da população e possui uma variedade de opção de propiciar atividades de lazer e encontros sociais.

Os frequentadores entenderam que os espaços são insuficientes, ao mesmo tempo que existem áreas de lazer, porém, para as camadas mais privilegiadas da população, como por exemplo os clubes particulares. Consideram que tem um abandono por parte do governo local e faltam investimentos para adequar ao uso os espaços públicos existentes. Esse grupo critica, ainda, as ocupações irregulares que impedem a aproximação da população ao lago, o que, certamente, estão corretos, pois existe uma lei de ocupação do entorno do Lago Paranoá que proíbe qualquer construção na faixa de trinta metros a partir da margem do lago e, ao projetar a sua construção, Lucio Costa, urbanista responsável pelo desenho arquitetônico de Brasília, definiu o livre acesso a todo entorno de seu espelho d'água.

Apesar do fascínio que o Lago Paranoá transmite para seus freqüentadores, é clara a insatisfação da população com os agentes públicos na parte de investimentos em infraestrutura, pois acredita-se que o espaço é muito mal aproveitado e que o governo local deveria investir mais na qualidade de vida dos moradores de Brasília.

Percebeu-se, ainda, a existência da formação de dois grupos, caracterizados pela renda, na forma de utilização deste espaço. O primeiro grupo pode ser definido como da classe social 


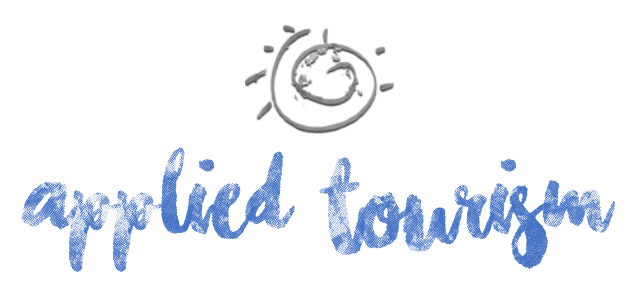

Volume 2, número 1,2017, p. 111-127

"A" que frequenta os locais mais bem instalados, com melhores condições de uso, e o segundo grupo, para a camada social menos favorecida economicamente, frequentando as instalações mais precárias, e, em sua maioria, para a prática da pesca.

O estudo identificou o descaso na orla do lago e que é possível investir no seu desenvolvimento, existindo interesse político em utilizar adequadamente a orla e criar parcerias com o setor privado, fornecendo vantagens para o investidor acreditar e despertar o interesse, pois o retorno será benéfico para todos os envolvidos.

Este trabalho fez parte das pesquisas realizadas para a dissertação de mestrado em Turismo e Hotelaria de Junqueira (2006) e contribui para pesquisas sobre as relações de lazer exploradas na orla do Lago Paranoá de Brasília, sendo possível servir de base em diversos estudos relacionados ao lazer, espaços urbanos públicos, tanto de Brasília e região quanto de outros lugares. Seu aprofundamento foi limitado devido às dificuldades encontradas em obter informações do setor público a respeito de documentos e análises da situação real do espaço explorado.

Sugere-se que novos estudos sejam realizados a partir de um mapeamento da orla do Lago Paranoá identificando e caracterizando as novas estruturas de lazer implantadas pelo governo em parceria com o setor privado nos últimos anos. Assim como recomenda-se que novas abordagens sejam realizadas para identificar as diversas percepções dos grupos sociais da população local. Para isso, o método do Discurso do Sujeito Coletivo pode contribuir na compreensão da interpretação dos espaços públicos de lazer pela comunidade que a utiliza para o lazer.

\section{REFERÊNCIAS}

Andrade, J. V. (2001). Lazer: princípios, tipos e formas na vida e no trabalho. Belo Horizonte: Autêntica.

Camargo, L. O. L. (2003). O que é Lazer. $2^{\circ}$ reimpr. da $3^{\circ}$ ed. São Paulo: Brasiliense.

Castells, M. (1983). A Questão Urbana. Trad. Arlene Caetano. Rio de Janeiro: Paz e Terra. 


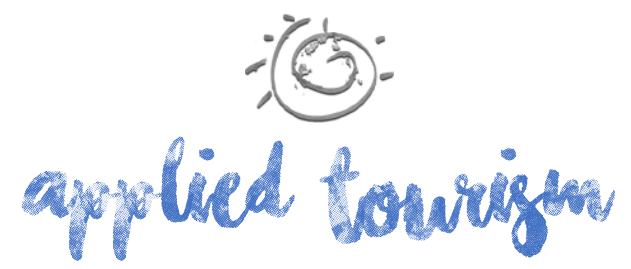

Volume 2, número 1, 2017, p. 111-127

Costa, L. (1991). Relatório do Plano Piloto de Brasília - Brasília, cidade que inventei. ArPDF, CODEPLAN, DePHA. Brasília.

Dumazedier, J. (2001). Lazer e Cultura Popular. $3^{\circ}$ Ed. $1^{\circ}$ Reimpressão. São Paulo: Editora Perspectiva. .(1999). Sociologia Empíricado Lazer. São Paulo: Perspectiva: SESC.

Gomes, P. C. C. (2002). A Condição Urbana - Ensaios de Geopolítica da Cidade. Rio de Janeiro: Bertrand Brasil.

Junqueira, L. D. M. (2006). Lago Paranoá de Brasília/DF: análise dos usos e ocupações do espaço da orla para o lazer. Dissertação de mestrado. Balneário Camboriú, SC. UNIVALI.

Lefèvre, F.; lefèvre, A. M. C. (2003). O Discurso do Sujeito Coletivo: um novo enfoque em pesquisa qualitativa (desdobramentos). Caxias do Sul, RS: EDUCS.

Marcellino, N. C. (2002). Estudos do Lazer: uma introdução. $3^{\circ}$ ed. Campinas, SP: Autores Associados.

Santos, M. (1997). Espaçoe Método. $4^{\circ}$ ed. São Paulo: Nobel. 